\title{
PROPOSAL OF METHODOLOGY FOR IMPROVEMENT OF COSTING IN THE SERBIAN DEFENSE ORGANIZATION
}

\author{
Nikola Pekić \\ Ministry of Defense of the Republic of Serbia, \\ Defense Policy Sector, Strategic Planning Department
}

Costings are absolutely essential to the efficient operation of any defense organization and an immediate effort should be undertaken in Serbian MoD to determine if the current models produce usable costing data, and if not, that effort should be discontinued immediately. ${ }^{1}$ This paper outlines a simpler and effective means to developing costing models. Based on this paper the requirements of the Serbian defense organization to adopt effective costing capability models could be as follows: decision by senior defense leadership to develop and implement basic costing models based on Western best practices using Excel as the basic vehicle on which the models are to be developed; decision by senior defense leadership that such data are inherently unclassified and are to be used throughout the entire defense organization to encourage the efficient use of resources. It is all but impossible to create within an organization a "costing culture" without current cost data made available to all planners and decisions-makers. As such, the results of the costings should be placed on the MoD's website and made accessible not only to the defense organization, but also the general public as well; decision to review current defense planning procedures to require that all plans are fully costed before they are considered by defense leadership; decision to utilize the results of the full implementation of the operational planning procedures methodology thereby shifting from costings based on platforms, systems, and static units to producing the costings of extent and prospective "capabilities".

Key Words: defense organization, cost, costing, cost model, deployment, new capability

\section{Introduction}

The conduct or performing of any action or activity under the realm of defense organization business necessarily means the consumption of some kind of resources, but mainly economic resources. Furthermore, within a resource management

\footnotetext{
*nikola.pekic@mod.gov.rs

${ }^{1}$ CCMR Report on the adoption of modern defense planning tools and techniques in the Serbian defense organization, 19 November 2012

${ }^{2}$ lbid.
} 
process, in our view, costing reflects the most essence process and provides potentially a powerful lever or tool of management over the entire defense organization, and not only defense organization rather any public or private sector as well.

\section{Relevance of costing in defense organization}

Within a defense organization, costing creates the necessary nexus and helps to understand fully relationships between interrelated and mutually conditioned processes from inputs, for given or relevant defense related plan, to outputs. Moreover, this means that costing should be embedded very deeply into the aforementioned plans and processes with the ultimate goal to support and provide as best as possible performance outcomes. In a defense organizational context this means to develop and sustain the vital defense organization and military capabilities with optimal defense resources allocations and consumption.

Further, taking into account the importance of costing and cost models as well, there is a pretty mess or better to say confusion, both in theory/literature and application/practice. This vexing situation can create a bad influence and confusion in the heads of top managers, so that there is a necessity of fully understanding the nature of a sound costing methodology and the capability to select and implement an appropriate model and supporting methodology as well.

The basic building blocks of costing are the operational measurements of consumed resources (resources include people, space, equipment, and consumables, these being the drivers of cost and levers of change). Such measurements enable managers to draw conclusions and make judgments about why (a) the organization's results turned out as they out as they did (performance evaluation), (b) what this means for the future (planning), and (c) the probable results of available course of action (analysis and alternatives) all of which comprise essential information for effective decision making. ${ }^{3}$ Also, the application of judgment in providing good decision support for the top management of defense organization requires a clearly understanding of why and how cost information is to be used. For instance, if the goal is an improvement of operational capabilities of the Serbian Armed Forces that requires changes and developments of new strategic-doctrinal framework. In other words, appropriate nomenclature is needed to support the effective management actions, both regarding the optimization of resources consumed and optimal performance (outcomes). The inclusion of measurement of resources as an explicit stage in the costing process and cost model development has a deliberate purpose of costing interpretation and related outcomes for defense decision makers. Costing for decision support is valuable for performance improvement, i.e., value creation, "what if" analysis, and the effective and efficient application of an enterprise's resources and processes. ${ }^{4}$ The need for decision support usually requires a deeper diagnostic insight into the causes of events (why they happened), a clear and direct connection to operations (to evaluate change options), and support to planning for desired future outcomes. ${ }^{5}$

\footnotetext{
${ }^{3}$ International Federation of Accountants, International Good Practice Guidance, Evaluating and Improving Costing in Organizations, July 2009, pp.5

${ }^{4}$ Ibid.

${ }^{5}$ Ibid., pp. 6
} 
Proposal of Methodology for Improvement of Costing In the Serbian Defense Organization

The relevance of costing and the cost models in defense organizations reflects through the techniques that reveal the key information for the critical development of options in the process of defense planning and, later on, their assessment and evaluation. Using costing effectively for decision making requires understanding clear, timely cause-and-effect relationships between an output and the inputs required to produce it. ${ }^{6}$

According to the International Good Practice Guidance for Evaluating and Improving Costing in Organizations there are six fundamental costing principles that will help organizations to evaluate and improve their approach to providing relevant and reliable managerial information, and thus according to my opinion, also could be applied within defense organizations to improve costing and defense organization management oriented to outcomes. This will enable, according to the context of aforementioned guidance, defense planers to provide a descriptive and historical view of costs and a predictive forward-looking view that together provide the basis for analysis, evaluation, planning, and decision support.

\section{Missing professional personal profile}

It is apparent that Serbian defense organization desperately needs professional defense accountants who will be capable of dealing with a broad base of capabilities in undertaking a variety of roles and missions of Serbian Armed Forces. These specific profiled professional cadres should provide and use costing information for defense resources management and support decisions made by operational Commanders as well. Moreover, professional defense accountants should have important roles to play in (a) ensuring that cost data are "fit for purpose", (b) clarifying decision requirements, and (c) deciding how best to present information and analysis. This includes considering the relevance of revenue and cost information to the range of factors and issues pertinent to a particular decision. ${ }^{7}$

In performing such roles, professional defense accountants, necessarily have to posses the professional perspectives and the individual contributions of skills of other disciplines, such as specific military knowledge and experience, operational level knowledge and managers' experience, economists, combat systems expertise, defense system analysts, all of whom provide valuable insights. The professional defense accountants who design, use, or collect cost information must work closely with many other parts of a defense organization to analyze and interpret this information for decision making. In most cases, they will need to delve below the level of detail recorded in the defense action plans and required for appropriate development of planning options. Management accounting skills should be focused on the correct modeling of financial and non-financial data to optimize a defense organization, its use of resources (and their costs), and its outputs. Also, professional defense accountants need to understand where and why data used for defense plan development sometimes could be inadequate to support manage-

\footnotetext{
${ }^{6}$ Ibid., pp. 8

${ }^{7}$ For more details look at International Federation of Accountants, International Good Practice Guidance, Evaluating and Improving Costing in Organizations, July 2009
} 
rial decisions, so that they can help defense organization to invest in developing an appropriate decision support model that is not impaired by the deficiencies of a system designed primarily for preparing financial statements. For example, where financial reporting standards typically focus on full cost, most decisions are marginal or incremental, and require robust information on fixed and variable costs throughout the organization. Furthermore, general ledger data is purely financial, yet the cause-and-effect relationships of operational inputs and outputs - and their cost impacts - are fundamental in identifying the actions needed to improve operational efficiency and effectiveness. Equally, professional defense accountants will inevitably involve in designing, developing, improving, and using costing models and techniques, so that as the supplier of costing information must have a continuing and close dialogue and relationship with those who prepare, analyze, and interpret cost information into inputs for defense plans, that reflect the changing needs of decision makers. Although the roles of supply of costing information and design/implementation of costing models can be separated, neither can be done well without appropriate knowledge of the other. Defense planers require advice on (a) identifying needed decisions, (b) what assumptions should apply to the inclusion/exclusion of specific costs, and (c) how costs change relative to changes in output or the quality of delivered outcomes. Moreover, professional defense accountants should undertake broader roles at a planning, plan implementation, and performance evaluation level. These roles involve delivering costing information that supports the preparation of plans and budgets, the accomplishment of strategic objectives for evaluating performance. ${ }^{8}$

\section{Key Principles of Evaluating and Improving Costing That Can Be Applied in Defense Organizations ${ }^{9}$}

The key principles underlying widely accepted good practice are:

1. The importance of costing to good financial management: the ability to identify, measure, interpret, and present the full costs as they relate to an organization's economic flow of goods and services, both historically and in a forward-looking context, is necessary for an informed understanding of the organizational drivers of profit and value.

2. Fitness for purpose: Cost information should be prepared in a manner appropriate to the specific context and purpose of its use, of which there are three principal applications:

- External reporting - historical and descriptive;

- Performance evaluation and analysis - interpretative and diagnostic;

- Planning and decision support - analytical and predictive.

\footnotetext{
${ }^{8}$ Context tailored from International Federation of Accountants, International Good Practice Guidance, Evaluating and Improving Costing in Organizations, July 2009

${ }^{9}$ Customized for purpose of the paper, and for practical guidance on implementing the principles see International Federation of Accountants, International Good Practice Guidance, Evaluating and Improving Costing in Organizations, July 2009
} 
3. Business model/reality driven: Cost models should be designed and maintained to reflect the cause-and-effect inter-relationships and the behavioral dynamics of the way the organization functions. The information needs of decision makers at all levels of an organization should be taken into account, by incorporating an organization's business and operational models, strategy, structure, and competitive environment.

4. Materiality/cost effectiveness: The design, implementation, and continuous improvement of costing methods, data collection, and systems should reflect a balance between the required level of accuracy and the cost of measurement (i.e., cost-benefit tradeoff), based on the competitive situation of the organization.

5. Comparability over time and methodological consistency: Cost information should be collected and analyzed systematically and in such a way as to ensure comparability over time, whether in a routine information system, or for a specific application and/or purpose.

6. Transparency and auditability: Definitions and sources of cost data, the operational and other non-financial data underpinning them, and the methods of calculating costs, should be transparent to all users and recorded and capable of review, risk analysis, and assurance.

Note, each principle independently applies; principles should not be seen as steps in a process.

Taking into account the aforementioned costing methodology and principles, the same could be supplemented by the twelve costing continuum levels presented and detailed described in Information Paper of International Federation of Accountants Evaluating the Costing Journey: A Costing Levels Continuum Maturity Model.

The costing maturity model aims to help professional accountants apply their judgment in determining where an organization's capability is for supporting internal managerial analysis and decisions. The model can also help an organization decide to which level it should aspire to a given organizational requirements and the decision needs of employees. As such, it is a self-assessment tool that can be used by professional accountants to discuss with colleagues their organization's current practice and to consider appropriate actions for improving performance evaluation and analysis - interpretative and diagnostic, and planning and decision support - analytical and predictive. Although, the maturity journey is represented in 12 separate levels, some organizations may find themselves in-between levels, or already at various places on the journey. The significance of this cost maturity model is to highlight that cost models and supporting systems should reflect the underlying reality of the way the organization works, as far as affordability and materiality allow, and within the context of the required business decisions. The cost maturity model can also help professional accountants to play a central role in educating users, including advising, for example, on the selection of costing methods, and cost measurement, and classification. ${ }^{10}$

\footnotetext{
${ }^{10}$ Information Paper of International Federation of Accountants Evaluating the Costing Journey: A Costing Levels Continuum Maturity Model, July 2009
} 


\section{Cost Models}

An effective costing capability is an essential defense planning tool, so that without accurate costing of discrete force units to date, Serbian defense top management are incapable of making financially-informed decisions regarding force structure options and missions as well.

\section{Cost Model - Deployment}

The purpose of this cost model is to provide the necessary cost information for decision making with respect to deployment. In the context of this model the term deployment implies any military operation abroad or in exercise context.

For the cost model development it is necessary take into account following assumptions:

- Mission is Defined;

- Activities have been identified;

- Requirements have been identified - Concept of Operations and Table of Organization;

- Available resources and gaps have been identified.

Further, next input in the cost model are costing parameters such as:

- Table of Organization (Force Structure - Personnel \& Equipment)

- Target Start Date

- Duration

- Mode(s) of Deployment/Re-deployment

- Frequency of Rotations

- Equipment Activity Rates

In the phases of planning, deployment, employment, sustainment and redeployment of the designated capability, the cost model needs to envisage cost assignment for the structured list of activities and objects as follows:

- Pre-deployment

- Planning

- Development of Concept of Ops, ROE, Table of Organization

- Liaison with Coalition Forces

- Recce

- Intelligence preparation

- Specific pre-mission training

- Assembling the Task Force,

- Medical screening and vaccinations

o Clothing (Environmental) - Boots, etc

- Mission-specific procurement

- Deployment

- Pay the Troops

- Coordinate Move (Move Team) 
- Conduct Move - En route sustainment and maintenance

- Ground Move - Personnel

- Operate and Maintain Vehicles

- Sustain Troops

- Ground Move - Equipment

- Operate and Maintain Vehicles

- Sustain Drivers

- Equipment Preparation for Transport

- Ground Transport - To/from Railhead

- Airlift - Personnel

- Operate and Maintain Aircraft

- Sustain Troops

- Sustain Aircrew

- Ground Transport - To/from Airport

- Airlift - Equipment

- Operate and Maintain Aircraft

- Sustain Aircrew

- Equipment Preparation for Transport

- Ground Transport - To/from Airport

- Sealift - Equipment

- Operate and Maintain Ship

- Container Rental

- Equipment Preparation for Transport

o Ground Transport - To/From Seaport

- Sustainment

- Pay the Troops

- Backfill Vacant Positions

o Protect the Troops

- Conduct Operations

- Provide Force Protection

- Conduct Emergency Operations

- Conduct Police Operations

- Conduct Air Operations

o Provide CIMIC "Like" Support to Local Population

- Provide Communications

- Conduct Intelligence

- Provide Operational Logistics Support

- Supply

- Transport

o Finance

o Food Services

- Administration

- Provide National Support

- Conduct Inspections

o Re-supply 
- Provide Medical Support (including Dental)

- Provide Morale and Welfare Programs

- Family Support

o Entertainment, Fitness

- Amenities (Movies, Newspapers, Magazines, etc)

- Home Communication

- Maintain Equipment

- Protect the Equipment

- Maintain Ground Transport Equipment

- Maintain Armaments Equipment

- Maintain Ships

- Maintain Aircraft

- Re-deployment

- Pay the Troops

- Repatriation Rest and Recreation Leave

- Dispose of assets and environment clean-up

- Coordinate Move (Move Team)

- Conduct Move - En route sustainment and maintenance

- Ground Move - Personnel

- Operate and Maintain Vehicles

- Sustain Troops

- Ground Move - Equipment

- Operate and Maintain Vehicles

- Sustain Drivers

- Equipment Preparation for Transport

- Ground Transport - To/from Railhead

- Airlift - Personnel

- Operate and Maintain Aircraft

- Sustain Troops

- Sustain Aircrew

- Ground Transport - To/from Airport

- Airlift - Equipment

- Operate and Maintain Aircraft

- Sustain Aircrew

- Equipment Preparation for Transport

- Ground Transport - To/from Airport

- Sealift - Equipment

- Operate and Maintain Ship

- Container Rental

- Equipment Preparation for Transport

- Ground Transport - To/From Seaport

Cost model consisting the following cost categories respectively broken down into the sub-categories:

- Personnel costs

- Salary

o Special Allowances 
Proposal of Methodology for Improvement of Costing In the Serbian Defense Organization

- Operation and maintenance costs

- Personnel Support

- Out Theatre Travel Allowances

- Field Operations Allowance

- Insurance

- Medical

- Living Allowance

- Food

- Clothing

- Laundry

- In-Theatre Travel

- Other costs

- Petrol Oil and Lubricants (POL)

- Spares

- Equipment/Facilities Operating

- Internal Servicing

- Contract maintenance

- Ammunition

- Commercial Transport

- Air/Sea Port Fees/Services

- Army Control and Command Network (ACCN)

- Office Supplies

- Communications

- Water

- Local Labor

- Other costs

- Capital costs

- Personal Equipment

- Mine Detection and Disposal

- Communications

o Other

These cost categories and sub-categories have to be assigned to relevant aforementioned activities and objects.

Calculation procedure of costs within the cost model envisages following steps:

1. Develop and perform the appropriate calculations using tools appropriate to the scope, significance, and materiality of the costing, customized spreadsheets, costing software, or other methods as appropriate. Document the calculations. For example: spreadsheets used to gather, classify and organize data can be integrated with complimentary spreadsheets to calculate the desired results.

2. Confirm that all of the headings and data (cost objects, cost base, drivers and activity rates) were accurately entered. Add notes where needed. Confirm that the formulae are correct.

3. Calculate and test results i.e. ensure results are mathematically accurate and all formulae work as expected. 
After finished calculation procedure of costs follows the procedure of results validation depicted in the following steps:

1. If practicable, reaffirm the validity of data sources, assumptions, methodology used and calculations by reconciling to financial reports, for the time period covered by the costing exercise. Document these efforts or explain why this is not practical.

2. Make efforts to reconcile the resulting cost information (in the cost objects) back to the cost base. For example: establish balancing formulas in results spreadsheets that link to original cost base spreadsheets. Document these efforts.

3. Reaffirm that the financial information used is from the appropriate and reliable sources and that no relevant sources have been overlooked. This requires consultation with information creators, maintainers, and users. Document these efforts.

4. Have an objective third party (colleague or other person with sufficient expertise) verify the mathematical accuracy of the calculations. Document these efforts.

5 . Test the reasonableness of the total cost/unit cost of the cost object by conducting sensitivity analysis (what if scenarios) to determine the impact of changes in the cost parameters. Document these efforts.

6. Confirm the validity of any non-financial information such as cost drivers and assumptions with knowledgeable users of the systems or information being costed. Document these efforts.

7. Did you need to calculate a unit cost? If yes, have you collected the appropriate output/outcomes volumes from the appropriate sources? Document these efforts.

8. Consult with stakeholders (internal/external) and senior management and confirmed that the results of the costing exercise respond to the purpose statement that was defined at the outset? Document these efforts.

9. Include in the documentation the requirement or recommendation that a post stage/deployment validation of cost estimates against actual costs be conducted and that the results of these validations be used to inform the estimates and refine the cost model.

After conducted validation phase document all actions and activities related to cost model development, submit documented cost model with appropriate memorandum/description to the responsible authority for approval. Further, after all deployments, conduct Post Operation Validation of Cost Estimates - Compare actual costs to cost estimates preferably at each stage of the deployment, but in any case, following the completion of each deployment to educate future cost estimates and refine the cost estimating process/model. This would involve the comparison of actual costs to cost estimates. Such validation could/should be incorporated into each stage of the Life Cycle Process.

\section{Cost Model - New Capability}

The purpose of this cost model is to provide the necessary information for decision making with respect to the introduction of a new capability. In the context of this model, the term capability implies the ability to deliver a specific service or perform specific activities to achieve established goals. This includes doctrine, structure, personnel, equipment, education, and training. 
Proposal of Methodology for Improvement of Costing In the Serbian Defense Organization

For cost model development it is necessary to take into account the following assumptions:

- capability is defined;

- activities have been identified;

- planning scenarios have been identified (How will the capability be used?);

- requirements have been identified - concept of operations and table of organization;

- available resources and gaps have been identified;

- Very rough order of magnitude cost estimates of capability justifies the costing effort.

Further, the next inputs in the cost model are costing parameters such as:

- target implementation date and time horizon

- potential options

- potential costing analogies

- potential cost estimating relationships

- cost of capital/discount rate

- financial threshold

- questions/considerations

o what are the outputs of the capability?

o what are the main definable components of the capability?

o can and/or should these components be costed separately?

In the phases of definition, implementation, operation and renewal of a new capability the cost model needs to envisage cost assignment for the structured list of activities and objects as follows:

- Definition (NATO Concept and Development) - including the identification of baseline supply and demand information (e.g., inventory information), service delivery options and business case analysis;

- project management

- study and analysis including research

- testing

- Implementation (NATO - Production) acquisition, or design and construction;

- project management

- study and analysis

- procurement

- reorganization

- training

- supporting infrastructure

- offset considerations

- support systems (C4ISR), Weapons, Maintenance)

- testing

- Operations (NATO - Utilization and Support) - asset in use and related service delivery, including performance reporting

- pay the troops

- operation

- maintenance

- overhaul 
- Renewal or disposal (NATO - Retirement) - end of an asset's useful economic life, or requirement for services is to be renewed or no longer needed

- study and analysis

- disposal

- extend useful life

- initiate acquisition of new equipment

Cost model consisting the following cost categories respectively broken down into the sub-categories:

- capital costs

o salary

o facilities

o office

o consulting

o equipment/hardware

o equipment/software

o initial spares

o transport

- personnel costs

o salaries

o allowances

- operation and maintenance costs

o petrol oil and lubricants (POL)

o spares

o contract maintenance

o travel allowances

o facilities

o disposal costs

These cost categories and sub-categories have to be assigned to relevant aforementioned activities and objects.

Calculation procedure of costs within the cost model envisages following steps:

1. Develop and perform the appropriate calculations using tools appropriate to the scope, significance, and materiality of the costing. Customized spreadsheets; costing software; or other methods as appropriate. Document the calculations.

2. Confirm that that all of the headings and data (cost objects, cost base, drivers and activity rates) were accurately entered. Add notes where needed. Confirm that the formulae are correct.

3. Calculate and test results, i.e. ensure results are mathematically accurate and all formulae work as expected.

After the finished calculation procedure of costs, there follows the procedure of results validation which has the same steps as aforementioned validation procedures in the cost model for deployment with the following phases of submitting for approval and, later on, post project validation of cost estimates where is needed to compare actual costs to cost estimates preferably at each stage of the project to educate future cost estimates and refine the cost estimating process/model. 


\section{Conclusion}

The introduction of an improved costing methodology supported by cost models into the Serbian Defense Organization will optimize and offer the solution for overcoming the current deficiency in the existing system that attempts to budget policy directly without sufficient attention paid to operational planning analysis and subsequent programming. Furthermore, the current framework of Serbian defense programs is seen as financial tools, vice activities-oriented general management/de-confliction/coordination tools. ${ }^{11}$ The depicted costing methodology in this paper offers guidelines how to develop further and expand cost models to provide and ensure better linkage to the existing spending categories. Moreover, cost models in support of the existing Serbian defense planning process should include standard operating costs for major systems and equipment (through the publication of a cost catalog) and on that way have an effect on efficiency and effectiveness of resources consumption.

\section{Reference}

[1] Information Paper of International Federation of Accountants Evaluating the Costing Journey: A Costing Levels Continuum Maturity Model, July 2009.

[2] International Federation of Accountants, International Good Practice Guidance, Evaluating and Improving Costing in Organizations, July 2009.

[3] Statement of Federal Financial Accounting Standards (no.4 1995), Managerial Cost Accounting Concepts and Standards for the Federal Government [web link].

[4] International Federation of Accountants (2000), Perspectives on Cost Accounting for Government, International Public Sector Study [web link].

[5] CCMR Report on National Assistance Program to the Republic of Serbia: Cost Models and Cost Factors, 26-30 September 2011.

[6] CCMR Report on The adoption of modern defense planning tools and techniques in the Serbian defense organization, 19 November 2012.

\footnotetext{
${ }^{11}$ For more details see CCMR Report on National Assistance Program to the Republic of Serbia: Cost
} Models and Cost Factors, 26-30 September 2011 